\title{
EVENTOS TROMBOEMBÓLICOS NA SÍNDROME NEFRÓTICA PEDIÁTRICA
}

\section{CATEGORIA: CLÍNICO}

INSTITUIÇÃO: CENTRO UNIVERSITÁRIO SÃO CAMILO

\section{AUTORES:}

MEGALE, Luisa1 - Rua Cristóvão diniz, 67, Cerqueira cesar;

luisamegale@hotmail.com, (11) 1198644-1758

GÓES, Leonardo ${ }^{1}$

MARIETTO, Déborah ${ }^{1}$

\section{ORIENTADORA:}

DIAS, Juliana²

1 Discentes da Faculdade de Medicina do Centro Universitário São Camilo

2 Docente da Faculdade de Medicina do Centro Universitário São Camilo 


\section{EVENTOS TROMBOEMBÓLICOS NA SÍNDROME NEFRÓTICA PEDIÁTRICA}

CATEGORIA: CLÍNICO

DESCRITORES: “Nephrotic Syndrome”; "Thromboembolism”; "Pediatrics” 


\section{Resumo}

Introdução: A síndrome nefrótica ( $\mathrm{SN}$ ) é uma das doenças renais pediátricas mais comuns e é caracterizada pela tríade de proteinúria, hipoalbuminemia e edema que acomete o gloméluro. Essa condição gera um estado de hipercoagulabilidade, sendo os eventos tromboembólicos uma complicação que acomete cerca de 3\% dos pacientes, sendo as tromboses venosas cerebrais as mais frequentemente observadas, seguidas por tromboembolismo pulmonar. Os eventos tromboembólicos relacionados à SN em crianças inclui a tendência trombofílica do paciente, riscos relacionados ao tratamento, e a hipercoagulopatia relacionada à doença decorrente de anormalidades na agregação plaquetária, aumento da síntese de fatores pró-trombóticos, perda urinária de proteínas anticoagulantes, fibrinólise alterada e depleção de líquido intravascular. Objetivo: Compreender e analisar as evidências da ocorrência de eventos tromboembólicos na Síndrome Nefrótica pediátrica. Metodologia: Revisão integrativa com busca de artigos no PubMed. Foram encontrados 41 artigos com os descritores Nephrotic Syndrome and Thromboembolism and Pediatrics. Após exclusão de artigos anteriores a 2014 e os que não se adequavam ao tema, sobraram 10 artigos que foram analisados. Resultados: Poucos estudos foram encontrados, dentre eles relatos de caso onde foram identificados níveis muito baixos de albumina e grande proteinúria no paciente no momento da trombose, mostrando uma relação entre esses fatores. Outros dois estudos identificaram trombose de artérias pulmonares e seios venosos cerebrais durante remissão da doença com corticoide, com presença de proteinúria de 3+/4+ durante evento. Em coorte retrospectiva com 34 crianças de 2,5 a 12 anos com tromboembolismo por complicação da síndrome nefrótica, a trombose venosa cerebral foi a complicação mais comum em $11(31,4 \%)$ crianças, seguida por tromboembolismo pulmonar em $9(25,7 \%)$ e trombose venosa profunda em 5 (14,2\%) crianças. Trombose de veia cava superior foi observada em uma criança. Infartos do sistema nervoso central foi observada em $7(20 \%)$ crianças e 2 crianças tiveram trombose das artérias periféricas. Outra coorte retrospectiva analisou 280 crianças de 0 a 18 anos que tiveram eventos tromboembólicos. Desses, apenas 20 (7.1\%) apresentavam síndrome nefrótica. Conclusão: Notou-se que os eventos tromboembólicos na síndrome nefrótica pediátrica são uma complicação rara que cursam com mau prognóstico. A sua ocorrência parece ter relação com a duração da doença e grau de proteinúria; assim como maior incidência em sítios como os seios venosos cerebrais e artérias pulmonares. 


\section{Introdução}

A síndrome nefrótica (SN) é uma das doenças renais pediátricas mais comuns e é caracterizada pela tríade de proteinúria, hipoalbuminemia e edema, em sua maioria de origem idiopática que acomete o gloméluro. ${ }^{1,2}$ Essa condição gera um estado de hipercoagulabilidade, sendo os eventos tromboembólicos uma complicação que acomete cerca de $3 \%$ dos pacientes. A fisiopatologia do tromboembolismo relacionado à $\mathrm{SN}$ em crianças é de natureza multifatorial e inclui a tendência trombofílica do paciente, riscos relacionados ao tratamento, e a hipercoagulopatia relacionada à doença decorrente de anormalidades na agregação plaquetária, aumento da síntese de fatores pró-trombóticos, perda urinária de proteínas anticoagulantes, fibrinólise alterada e depleção de líquido intravascular. ${ }^{1,2,3}$ Diversos outros fatores físicos contribuem para a ocorrência da trombose na SN como a hipovelemia, hemoconcentração, aumento da viscosidade sanguínea e estase venosa. ${ }^{4}$

O tromboembolismo é um evento que apresenta grande risco de vida, com taxa de mortalidade de $2-8 \%$. Ele ocorre pela presença de um bloqueio na passagem de sangue pelo vaso graças à formação de um êmbolo. O êmbolo é formado por um desequilíbrio na tromboregulação alterando assim a Tríade de Virchow, caracterizada por estase sanguínea, lesão endotelial e coagulopatia. ${ }^{5}$

\section{Objetivo}

O objetivo do presente trabalho foi compreender e analisar as evidências da ocorrência de eventos tromboembólicos na Síndrome Nefrótica pediátrica.

\section{Métodos}

Trata-se de uma revisão integrativa com busca de artigos no PubMed. Foram encontrados 41 artigos com os descritores "Nephrotic Syndrome" and "Thromboembolism" and "Pediatrics". Após exclusão de artigos anteriores a 2014 e os que não se adequavam ao tema, sobraram 10 artigos que foram analisados. Optou-se por analisar todo o material disponível que se adequasse ao objetivo da pesquisa. A busca resultou em um total de 10 artigos, que foram analisados. 


\section{Resultados e Discussão}

A SN gera um estado de hipercoagulabilidade, sendo os eventos tromboembólicos uma complicação bem reconhecida que acomete cerca de $3 \%$ dos pacientes, sendo as tromboses venosas cerebrais as mais frequentemente observadas, seguidas por tromboembolismo pulmonar, trombose intracraniana profunda e, menos frequentemente, trombose venosa profunda de membros inferiores e artérias periféricas. ${ }^{2,3,6}$ Durante os 7 anos do estudo de Suri et al. (2014) 6 , um total de 34 crianças (22 meninos e 12 meninas) tiveram 35 eventos trombóticos. A trombose venosa cerebral foi a complicação mais comum em 11 (31,4\%) crianças, seguida por tromboembolismo pulmonar em $9(25,7 \%)$ e trombose venosa profunda em $5(14,2 \%)$ crianças. Trombose de veia cava superior foi observada em uma criança. Trombose arterial com infartos do sistema nervoso central foi observada em 7 (20\%) crianças e 2 crianças tiveram trombose das artérias periféricas.

Suri e colaboradores $(2014)^{6}$ encontraram fatores de risco trombóticos, como hipoalbuminemia grave, infecções, punções arteriais ou venosas e comprometimento de volume sanguineo.

Ishiguro et al. (2017) ${ }^{5}$ realizou uma coorte retrospectiva com 280 meninas e meninos de 0 a 18 anos com eventos tromboembólicos. Desses, 20 (7.1\%) pacientes apresentavam SN. O estudo, no entanto, não informou os locais dos eventos trombóticos.

Além dos estudos primário, 5 relatos de caso foram analisados:

- Menino de 2 anos e 10 meses com SN há 1 mês tratado com corticoterapia, evidenciou trombose de seio sagital superior e seio transverso. ${ }^{7}$

- Meninos de 2 e 15 anos com SN primária e trombose de seio venoso no início da doença. Ambos apresentavam níveis muito baixos de albumina e grande proteinúria $(245 \mathrm{mg} / \mathrm{m} 2 / \mathrm{h})$ durante a trombose. ${ }^{8}$

- Menino de 5 anos com SN há 1 mês e trombose bilateral de artérias pulmonares e seios venosos cerebrais durante remissão da doença com corticoide. A proteinúria apresentava-se em 3+/4+ durante evento trombótico. ${ }^{9}$

- Menino de 3 anos com SN diagnosticada 1,5 anos após apresentação da doença, apresentou tromboembolismo pulmonar durante remissão da doença com corticoide. ${ }^{10}$ 
- Menina de 16 anos com SN recidivante de longa data, apresentou trombose de veia cava inferior e veia renal. ${ }^{11}$

\section{Conclusão}

Notou-se que os eventos tromboembólicos na síndrome nefrótica pediátrica são uma complicação rara que cursam com mau prognóstico. A sua ocorrência parece ter relação com a duração da doença e grau de proteinúria; assim como maior incidência em sítios como os seios venosos cerebrais e artérias pulmonares.

No entanto, poucos estudos foram encontrados sobre o tema, sendo necessários mais trabalhos primários para identificação de prevalência, curso e fatores associados a essa complicação.

\section{Referências}

1. KERLIN, Bryce A.; HAWORTH, Kellie; SMOYER, William E. Venous thromboembolism in pediatric nephrotic syndrome. Pediatric Nephrology, v. 29, n. 6, p. 989-997, 2014

2. NOONE, Damien G; LIJIMA, Kazumoto; PAREKH, Rulan. Idiopathic nephrotic syndrome in children. Lancet 2018; 392: 61-74

3. PASINI, Andrea et al. The Italian Society for Pediatric Nephrology $(\mathrm{SINePe})$ consensus document on the management of nephrotic syndrome in children: Part IDiagnosis and treatment of the first episode and the first relapse. Italian journal of pediatrics, v. 43 , n. 1 , p. 41,2017

4. MORALES, José Vanildo; VERONESE, Francisco José Veríssimo; WEBER, Raimar. Fisiopatologia e tratamento da síndrome nefrótica: conceitos atuais. Revista HCPA. Porto Alegre. Vol. 20, n. 3 (nov. 2000), p. 290-301, 2000.

5. ISHIGURO, Akira et al. Pediatric thromboembolism: a national survey in 
Japan. International journal of hematology, v. 105, n. 1, p. 52-58, 2017

6. SURI, Deepti et al. Thromboembolic complications in childhood nephrotic syndrome: a clinical profile. Clinical and experimental nephrology, v. 18, n. 5, p. 803-813, 2014

7. TORRES, Ronaldo Afonso et al. Venous sinus thrombosis in a child with nephrotic syndrome: a case report and literature review. Revista Brasileira de terapia intensiva, v. 26, n. 4, p. 430-434, 2014.

8. KURT-ŞÜKÜR, Eda Didem et al. Two children with steroid-responsive nephrotic syndrome complicated by cerebral venous sinus thrombosis. nefrologia, v. 35, n. 5 , p. $497-500,2015$

9. KUMAR, Mritunjay et al. Thromboembolic complications at the onset of nephrotic syndrome. Sudanese journal of paediatrics, v. 17, n. 2, p. 60, 2017

10. SANDAL, S. et al. Pulmonary thromboembolism: A rare but serious complication of nephrotic syndrome. Indian Journal of Nephrology, v. 28, n. 3, 2018

11. HERAN, Manraj Kanwal Singh; COUPAL, Tyler Michael; DIONNE, Janis. Endovascular pharmacomechanical thrombolysis-a novel treatment for circumaortic left renal vein and inferior vena cava thrombosis in a paediatric patient with relapsing nephrotic syndrome. BJR| case reports, v. 4, n. 2, p. 20170082, 2018 